\title{
Inspiration and fixation: the influences of example designs and system properties in idea generation
}

\author{
Luis A. Vasconcelos ${ }^{1}$; Carlos C. Cardoso ${ }^{2}$; Maria Sääksjärvi ${ }^{2}$, Chih-Chun Chen ${ }^{1}$; Nathan Crilly ${ }^{1}$ \\ ${ }^{1}$ Department of Engineering Design \\ University of Cambridge \\ Trumpington Street, Cambridge, CB2 1PZ \\ United Kingdom \\ \{lal40, ccc54, nc266\}@cam.ac.uk
2 Faculty Industrial Design Engineering
Delft University of Technology
Landbergstraat 15, Delft, 2628CE
The Netherlands
\{c.m.cardoso, m.c.saaksjarvi\}@tudelft.nl

\section{ABSTRACT}

When tackling problems, designers might be inspired by different sources, whether concrete or abstract. The more concrete sources often comprise representations of potential solutions or examples of existing designs. The more abstract sources often represent the desirable properties of engineered systems, such as modular system architectures. We performed an experiment with sixty novice designers to compare the inspiration effects from these two types of stimuli. Participants were asked to solve a design problem, having been exposed to either a concrete example design, an abstract system property, both, or no stimulus at all. Their design work was assessed according to four metrics: fluency, diversity, commonness, and conformity. Exposure to either the example design or the system property reduced the fluency and diversity of ideas, and exposure to both stimuli reduced these measures even further. Whilst there was no difference in the inspiration effects from the example and the property in terms of fluency, diversity, and commonness; results for conformity showed that each stimulus constrained participants differently: encouraging ideas similar to one type of stimulus while discouraging ideas similar to the other type. In combination with other work on inspiration and fixation, these findings can help shape how design is taught and how inspiration tools are developed.

Keywords: Conceptual Design, Creativity and Concept Generation, Design Process, Design Theory and Methodology, Product Design, Systems Engineering 


\section{Introduction}

Designers often use sources of inspiration when trying to frame the problem at hand and explore possible solutions. They might encounter these sources in different ways, such as purposely consulting them or simply encountering them in the environment [1-3]. Additionally, the inspiration sources might take different forms, including representations of potential solutions (such as existing products and biological analogues) or more abstract properties (such as design heuristics and design attributes). Regardless of how these external inspiration sources are encountered and what form they take, it is important to understand the effects that they have on idea generation. Otherwise, there is the risk that designers search for or are provided with stimuli that are either irrelevant or actually counterproductive.

In research into design creativity, many empirical studies have investigated the role of external sources of inspiration during idea generation. It has been found that whilst external stimuli may unlock the designers' imagination and boost the generation of ideas, they can also constrain the designers' exploration of the design space, causing them to blindly adhere to a limited set of ideas - an effect described as design fixation [4,5]. Since it was first described, design fixation has become a popular research topic, with studies now conducted across different engineering disciplines. This wealth of research has attracted literature reviews focused solely on design fixation, investigating the concepts discussed [6], the research methods used [7], and the findings obtained [8]. These reviews show that although fixation studies have presented participants with a great variety of external stimuli, those stimuli typically have one characteristic in common: they are examples of potential solutions, products or designs [9-14].

Although it is seldom explained, the use of example designs in fixation studies might be motivated by a number of different aspects of design practice, including designers' preference for such stimuli or their familiarity with existing products or previous projects [15]. However, example designs can hinder creativity and diminish opportunities to consider a wider range of alternatives [16]. Example designs may also lead designers to focus on certain 'superficial' details of the inspiration source (such as the shape of a product), while ignoring the 'underlying' properties that those examples embody $[17,18]$. 
For instance, modularity and adjustability are important properties of engineered systems [19], and designers might seek inspiration from technical, biological, computational or organizational systems that exhibit those properties [20]. However, since such abstract properties require specific background knowledge and a higher cognitive effort to be interpreted, they might be overlooked when example designs are also available, meaning that valuable information could be lost in the inspiration process. Whilst research into inspiration and fixation has extensively investigated the influence of concrete examples in idea generation, there has been no such investigation on the influence of abstract systems properties (also sometimes referred to as system lifecycle properties [21-23]). Therefore, what should we expect from these two distinct forms of stimuli, when they both represent equally viable approaches to solve the same problem?

In this paper, we report on an experiment designed to investigate whether the inspiration and fixation effects that have been found for example designs might also be found for system properties, and how these two stimuli types interact. In particular, we tested the hypothesis that when participants are working on a design problem to which one part of the solution space is to design for adaptability, they will be affected differently by a representation of an example design (i.e. a product that is adjustable) than they are by a representation of a system property (i.e. modularity). As such, although we are interested in example designs and system properties more generally, in this paper we focus on one instance of each stimuli type. We adopted an experimental method typical of that described in the design fixation literature, in which participants generate multiple solutions to a given problem solutions that are later assessed according to criteria such as quantity and diversity. In the experiment, we define design fixation as a limitation of the creative output due to the repetition of a previous concept into subsequent concepts, irrespective of how flawed the concept might seem or how conscious of the repetition the designer might be. However, before describing the experiment and discussing its results, it is first necessary to situate this work relative to prior work on inspiration and fixation, and also that on concrete example designs and abstract system properties. 
Inspiration and fixation. Everyone can become inspired. Inspiration can arise either from internal or external stimuli - whilst internal inspiration depends on someone's previous experience and background, external inspiration describes the use of other information sources, such as physical objects and encoded media [24]. External sources may help establishing connections between apparently disjointed information and elements, and these connections are often described in the literature as analogies. Analogies are characterized as a cognitive process in which information is transferred from one domain (the source) to another domain (the target). They are also fundamental for human cognition and creativity [25,26], thus being a powerful mechanism to connect the inspiration drawn from external stimuli to the generation of creative designs.

In design research, many studies have observed the influence of external stimulation on designers' ability or propensity to draw analogies during idea generation [12,27-30] and many tools have been proposed to inspire designers with the use of external stimuli [31-34]. With respect to the stimuli used, inspiration depends on two main aspects: what is being shown (content) and how it is being shown (representation) [35]. It was found that depending on the stimuli used and how they are introduced, inspiration effects can be both positive [36-40] and negative [11,12,41-43]. These negative effects are broadly referred to in the literature as design fixation. Fixation usually refers to an effect originally described in the experimental psychology literature [44-46], an effect in which an individual might unconsciously focus on certain aspects of an object or a task, whilst leaving out other aspects. The relevance of fixation to the creative process has made it an important topic among the design research community. Collectively, the experiments conducted to date have manipulated many variables (see $[7,8]$ ), including stimuli-related aspects (such as the number of stimuli and how they are represented to participants) as well as procedure-related aspects (such as the number of designers involved and the total working time available for the design task). By manipulating such variables, researchers have found many causes for fixation and how to avoid them $[10,47,48]$. Despite the variety of design fixation studies that have been conducted, so far researchers' have mainly focused on the influence of stimuli that represent concrete example designs. 
Concrete example designs. Example designs are either existing objects or representations of possible objects. They are often used to illustrate potential solutions to a design problem, and are also adopted as external inspiration sources during the design process [2], whether they are represented pictorially or verbally. Example designs can also be characterized by having either a physical referent (in the case of real objects) or a description of their function, structure and behavior (in the case of more intangible systems). As such, they can be considered as concrete entities, since they can or do actually exist, and are therefore interpreted quite consistently. Similarly, there are concrete examples of naturally occurring entities, such as trees and animals, which can also be used to inspire idea generation and foster analogical transfer [49,50] - a process often described as biologically inspired design, bionics, biomimetics or biomimicry [51]. Thus, whether inspiration sources represent man-made or naturally occurring entities, they can all be defined and used as example designs.

Example designs are often encountered in the early-stages of design, when designers search for existing solutions as a means of exploring the problem [52], which is intended to help their creative process. However, the literature points to a different direction: when studies used example designs as external sources of inspiration, the effects on participants tended to be negative, resulting in some sort of design fixation. Example designs were used for tasks such as designing a bicycle rack [5], a device to pick books from high shelves [53], a peanut shelling device [11,54], a unit to pump petroleum [55], an automatic watering device for house-plants $[40,56]$, and a small vehicle to be launched from a ramp [57]. For design tasks such as these, researchers found that providing the participants with either 2D or 3D representations of an example design resulted in constraining effects, ranging from an increase in the repetition of features from the examples, to a decrease in both the quantity and the variety of solutions. Generally, these results indicate that instead of positively inspiring designers, example designs tend to fixate them.

Abstract system properties. An alternative to providing designers with concrete example designs is to provide them with abstract system properties. These properties are also referred to in the literature as "ilities" [21,58] or system lifecycle properties [20,22]. Here we define such abstract properties as 
desirable attributes or behaviors of an engineered system (or product), especially if that system should accommodate change. Examples include modularity, redundancy, adaptability, robustness, scalability and many others. These properties are widely applied in various design practices, such as engineering, software, service, and industrial design; and can be found across a wide variety of other systems, such as biological, social, and technical systems [59]. As such, these properties might be generally applicable to many kinds of design problems and are recommended through many different sources, such as design texts [19,60,61], design methods [62,63], and analogical design tools [31,64].

Although example designs and system properties can both be considered inspiration sources, they are essentially different with respect to their content and representation. Example designs are concrete entities, whereas system properties are immaterial concepts. As such, these properties can be considered abstract entities, since they do not have a physical referent and can be interpreted with respect to different scales and fields of application. Additionally, example designs often illustrate the structure and function of specific solutions (i.e. how they look and what they do), whilst system properties emphasize the underlying attributes that can be embodied in such solutions.

It is important to note that we are here using the term 'abstract' (as in 'abstract system properties) in a particular way. We consider the level of abstraction of the content of the inspiration sources and not the level of abstraction of the representation of the inspiration source - an aspect that has already been the subject of comprehensive investigation $[27,65,66]$. As such, the term 'abstract' might be used in other ways in the literature, describing different variables that are being manipulated. For instance, when observing the effects of abstract stimuli during idea generation, some researchers refer to abstraction as the 'distance' between inspiration source and problem, and focus only on textual stimuli [67]. This is similar to a series of other studies that have investigated the effects of stimuli-problem proximity $[11,41,68-70]$. Other studies have manipulated the abstraction of both problem statement and problem representation, without manipulating the stimuli [71]; have used a set of heuristics based on functional requirements, customer needs, and user activities, and have manipulated inspiration techniques, without manipulating the stimuli [28]; and have used a set of heuristics similar to those found in Synectics [72] and to the structural transformations and idea refinements found in TRIZ [62] 
and SCAMPER [63], without comparing the effectiveness of such stimuli and an actual example design [73]. More relevant here are studies that compared the inspiration sources of concrete and abstract content $[74,75]$. However, these either did not provide specific stimuli to participants (but directed them to think of stimuli themselves) [74] or did not ask participants to solve a design problem (but required them to propose both a design problem and a corresponding solution) [75]. Generally, all these studies have produced results that support the use of more abstract sources of inspiration during the design process.

There is more evidence that incorporating more abstraction into the inspiration method can bring benefits to the design process. Some sort of stimuli abstraction was used for tasks such as inventing new modes of human transportation [67], devising a way to reduce overdue accounts or unpaid credits [28], and designing a set of salt and pepper shakers [73]. For these design projects, researchers found that providing participants with a short story, functional requirements, or design heuristics, respectively, resulted in positive effects, ranging from less repetition of features from examples to an increase in the diversity, originality and quantity of solutions. These results indicate that abstraction can help inspire designers or mitigate fixation. However, there has been no research directly comparing the effects of presenting designers with an abstract system property and a concrete example designs. We conducted an experiment to understand how these two distinct inspiration sources may affect the work of designers during idea generation.

\section{Methodology}

Objective and hypothesis. This experiment investigates how different stimuli influence the inspiration and fixation effects observed in design work. We manipulated what form of stimuli designers were provided with: an abstract system property (i.e. modularity), a concrete example design (i.e. an adjustable bicycle), neither or both. For clarity, we understand modularity to be the encapsulation of a set of elements into components that can be treated independently with respect to their functions and that share a common interface independent of their internal structures. 
Our major hypothesis was that example designs and system properties will affect the designers' generation of ideas in different ways. We additionally included a mixed condition in order to test whether idea generation would be helped or hindered by showing both a concrete example and an abstract property, but also to observe which stimulus would have stronger effects and whether the exposure to an additional abstract stimulus would defixate participants. This hypothesis can be broken down into more specific predictions described below. We understand design fixation to be the limitation of creative output due to the repetition of a previous concept into subsequent concepts. This would imply decreased productivity of the participants as well as increased idea repetition. As such, we expect system properties and example designs to inspire designers differently with respect to four metrics:

- Fluency (or quantity of ideas): the system property will provide indirect approaches to solve the problem without defining a specific range of solution possibilities, thus participants exposed to the property (property group) will generate more ideas than those exposed to the example design (example group);

- Diversity (or exploration of the solution space): system properties have flexible definitions and can be applied to several different domains and at different scales, thus participants exposed to the property will comprehend it from different perspectives and will generate more varied ideas than those exposed to the example design;

- Commonness (or unoriginality of ideas): as the system property will enable greater variety of ideas, participants exposed to the property will also be more likely to explore more uncommon (or rare) and original ideas than those exposed to the example design;

- Conformity (or repetition of the stimulus): the system property will stimulate the generation of ideas that use that same property (participants exposed to the modularity property will create more modular ideas), whereas example designs stimulate the generation of ideas that are from the same type of example being shown (participants exposed to the bicycle example will create more bicycle ideas).

The predictions above are summarized in Table 1. 
Table 1. Summary of the experimental predictions

\begin{tabular}{llllll}
\hline Group & Stimulus & Fluency & Diversity & Commonness & Conformity \\
\hline Baseline & None & Very high & Very high & Very low & None \\
Property & Modularity & High & High & Low & Modularity \\
Example & Bicycle & Low & Low & High & Bicycle \\
Mixed & Both & Very low & Very low & Very high & Bicycle \\
\hline
\end{tabular}

Additionally, as a consequence of the previous predictions, we also expect to observe the following effects:

- Example prevalence: inspiration effects from the example design will be dominant, i.e. participants will be more influenced (either inspired or fixated) by the bicycle example than by the modularity property; thus participants exposed to both stimuli (mixed group) will generate ideas that are similar to ideas from participants exposed to the bicycle example;

- Conceptual gravity: in comparison to the other participants, those exposed to both stimuli will generate fewer ideas because they will be 'doubly fixated', and since modularity and adjustability are closely related to adaptability, this will increase the extent to which participants are drawn towards the idea of adaptability.

- Beneficial isolation: participants exposed to no stimuli (baseline group) will present the best results for fluency, diversity, commonness, and conformity, because they will not be fixated by any stimuli.

Experimental method. Each experimental session lasted for one hour, comprising time for instructions, idea generation, completion of a questionnaire, and debrief. The participants were verbally asked to be creative and to design, individually, as many ideas as possible to a given problem. They were also asked to sketch and describe in writing their ideas on sheets of paper, with each idea on a separate sheet. Participants were randomly allocated to four experimental conditions: those in the baseline group were not provided with any external stimulation; those in the property group were provided with a diagram and a written description of modularity; those in the example group were 
provided with a sketch and a verbal written description of a bicycle example; those in the mixed group were provided with both the example and then later with the property.

At the end of the session, the participants' work was collected (in the form of sheets of paper containing annotated sketches of their ideas). Each sheet was marked with a code that did not associate the work with any experimental group or individual participant. This was to ensure that those evaluating the work would be blind to such information. The work was later assessed by evaluators against the creativity and fixation metrics introduced above.

Participants. Sixty Masters students (36 women and 24 men; mean age of 23.5 years, SD = 1.66) in Industrial Design Engineering from TUDelft (The Netherlands) were assigned to one of the four groups $(n=15)$. We checked the design experience of the participants (mean experience of 4.71 years, $\mathrm{SD}=$ $1.10)$ and whether they had designed for the problem before $(<7 \%)$ in order to measure the homogeneity of the sample with respect to design proficiency and familiarity with the design problem. Participation in the experiment was voluntary; participants received a monetary reward in exchange for their time.

Task and problem. The participants were required to generate design ideas in response to the following problem. "Bicycles are a popular mode of transportation and recreation for many people. While growing up, a person might go through a series of ever-larger bikes, sometimes having several models, one after the other. However, having several bikes can be a problem for many reasons. Your task is to generate as many ideas as possible to eliminate the need to have multiple bikes as people grow up."

This problem was selected because it was expected to satisfy the following three criteria. First, it was unlikely that the participants had designed solutions to it before, thus offering equal levels of difficulty across all the experimental conditions - on the other hand, they were likely to have experienced the situation described in the problem previously (i.e. while growing up, they had probably progressed from one bicycle to the next), thus helping them to connect with the problem and understand the need to solve it. Second, the problem could be solved in many different ways, with 
many different underlying properties being applied, thus leaving enough room for creativity. At the same time, it was expected that developing an 'adaptable' solution would be a common way of solving this problem, an approach that could equally be realized by invoking the modularity property (e.g. by interchangeable parts) or adjustability (e.g. by telescoping parts). Finally, both the design brief and the potential ideas held a low level of complexity, thus being suitable for a thirty-minute idea generation experiment.

Procedure overview. Experimental sessions were conducted in a large classroom, with participants seated in every other seat to prevent interference with each other's work. The procedure took approximately fifty minutes in total. During the first five minutes, all participants listened to spoken instructions for the activities to follow. They were explicitly asked not to concern themselves with the time (they were told when to start and stop the activities), not to interrupt the idea generation process for any reason, and not to worry about the level of details of the ideas nor to spend too much time on one single idea. After the instructions, the participants received the design brief on a sheet of paper and were asked to think of ideas for three minutes, without actually committing any designs to paper (as different participants had different materials and content, this ensured they all had enough time to read all the materials and start developing some ideas). Along with the brief, participants in both the example and the mixed groups received a separate sheet of paper containing the example design, whereas participants in the property group received a sheet of paper containing the system property. The stimuli were introduced to participants in the stimulated groups (property, example, and mixed) as follows. 'Here is a concept that illustrates one way to solve this problem'. After the three minutes of preparation, all participants had thirty minutes to generate ideas, recording only one idea per sheet of paper. After fifteen minutes of design work, the participants in the mixed group were then provided with the system property. The other participants received a sheet of paper with no additional stimuli on it, but only an explicit instruction to keep designing (this way all groups were interrupted in a similar way). After the idea generation period, all participants had five minutes to complete a questionnaire in which previous experience and knowledge were reported, as well as demographic 
information. Finally, participants had some time to discuss the procedure and general idea of the study with the experimenters during the debriefing. Table 2 illustrates the procedure for each experimental group.

Table 2. Summary of the procedure in the experiment

\begin{tabular}{c|c|c|c|c|c}
\hline $\begin{array}{c}\text { Time } \\
\text { (minutes) }\end{array}$ & $\begin{array}{c}\text { Duration } \\
\text { (minutes) }\end{array}$ & Baseline & Property & Example & Mixed \\
\hline $00-05$ & 05 & \multicolumn{4}{|c}{ Oral instructions } \\
\hline $05-08$ & 03 & $\begin{array}{c}\text { Design } \\
\text { brief } \\
\text { and time } \\
\text { to think }\end{array}$ & $\begin{array}{c}\text { Design brief, } \\
\text { modularity } \\
\text { stimulus, and time } \\
\text { to think }\end{array}$ & $\begin{array}{c}\text { Design brief, } \\
\text { bicycle stimulus, } \\
\text { and time to think }\end{array}$ & $\begin{array}{c}\text { Design brief, } \\
\text { bicycle stimulus, } \\
\text { and time to think }\end{array}$ \\
\hline $08-23$ & 15 & \multicolumn{4}{|c}{ Idea generation } \\
\hline $23-26$ & 03 & \multicolumn{4}{|c}{$\begin{array}{c}\text { Modularity } \\
\text { Interruption sheet } \\
\text { to think }\end{array}$} \\
\hline $26-41$ & 15 & \multicolumn{4}{|c}{ Idea generation } \\
\hline $41-46$ & 05 & 04 & \multicolumn{4}{c}{ Questionnaire } \\
\hline $46-50$ & 04 & \multicolumn{4}{c}{ Debrief } \\
\hline
\end{tabular}

Materials. All participants received the same design problem written on a sheet of A4 paper, as well as blank A4 sheets to sketch and annotate their own ideas. They also received pens and the questionnaire sheet. Apart from that, additional materials were given to participants according to their experimental group. Participants in both the property and the mixed groups received one sheet with a diagram and a written description of modularity, preceded by 'Here is a concept that illustrates one way to solve this problem' (Fig. 1). Participants in the example and the mixed groups received one sheet with a sketch and a written description of a bicycle, preceded by 'Here is a concept that illustrates one way to solve this problem' (Fig. 2). Participants in the mixed group received a notice at half time, which read: 'You are halfway through. Here is a concept that illustrates one way to solve this problem' (i.e. the diagram and description of modularity); all other participants received a 'halfway' interruption sheet with 'You are halfway through. Please keep going'. 


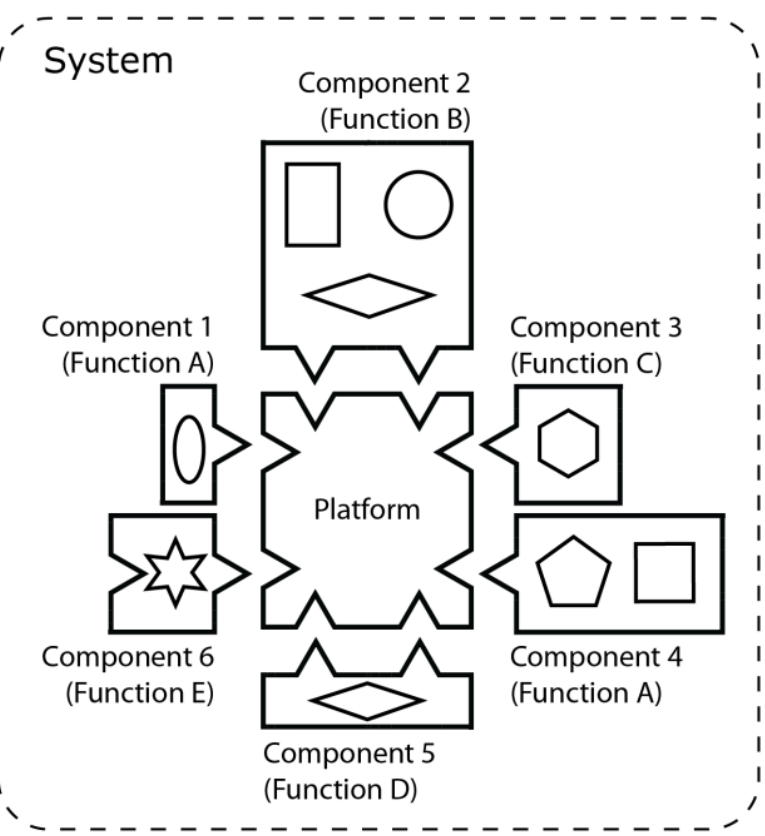

Fig. 1. Diagram representing the modularity property provided to participants along with the following description: "Modularity: the encapsulation of a set of elements into components that can be treated independently with respect to their functions and that share a common interface independent of their internal structures".

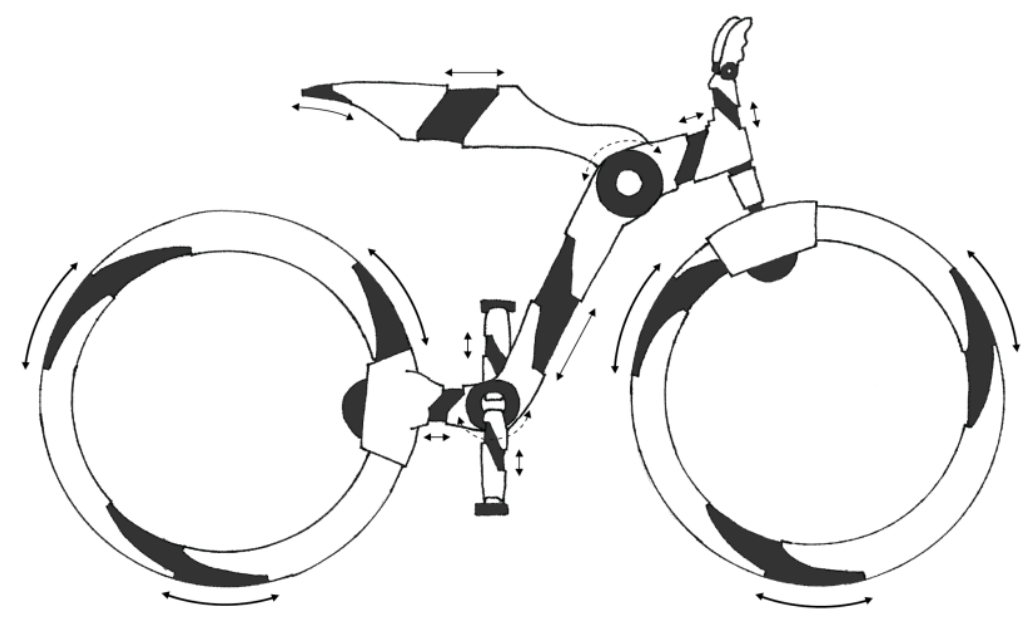

Fig. 2. Example solution provided to participants along with the following description:

"A telescoping bike with parts that can be extended or shortened to fit people with very different heights. Apart from the adjustable tubes and wheels, the angles between tubes can also be modified in specific joints". The sketch used is a modification of the Zee-K Ergonomic Bike [76]. 
Analysis. The analysis was divided into two complementary parts. In the first part, two authors of this study assessed the design work of the participants. The evaluators' backgrounds included industrial design and mechanical engineering; they were also familiar with assessing the design work of students and each had at least 10 years of experience in design research. One evaluator assessed all the ideas and the other assessed a random subset of the ideas in a random order, comprising half of all ideas. Before the assessment, the evaluators had a training session in which the process was discussed, the metrics were clarified and any questions were answered. The evaluators were unaware of which ideas originated from which groups. They considered 'one idea' to be a sheet of paper containing any understandable approach to solve the problem. As such, one idea could comprise two or more distinct approaches to solve the problem (e.g. a bike that grows organically and also gets decomposed). These distinct approaches were only considered later when analyzing the diversity and commonness of ideas.

The only strictly objective metric used in this first part of the analysis was fluency, i.e. the number or quantity of ideas generated per participant. Subjective metrics were originality, feasibility, practicality, overall quality, and conformity (or repetition of the stimulus), each of which is commonly found in similar studies [7]. Conformity might occur at different levels, for instance, repetition on the level of idea types (e.g. a product) and repetition on the level of properties (e.g. having telescoping tubes). With respect to the idea type, we divided the ideas into two broad categories: bicycle ideas and non-bicycle ideas, thus by generating an idea that is a bicycle, the participant would be repeating the same idea type. With respect to the property, we also divided the ideas into two categories: modular ideas and non-modular ideas, thus by generating an idea that is modular, the participant would be repeating the property.

All ordinal metrics were rated on a 5-point scale, while nominal metrics were rated as true or false. After assessing the ideas, the agreement between the two evaluators was calculated and is shown in Table 3. Because of low agreement between evaluators for specific metrics (in particular, those that are ordinal), the only metrics from this first part that we incorporated into analysis were the nominal ones. Once feasibility was the only ordinal metric that reached a good agreement, we decided not to use it in our analysis. 
Table 3. Inter-rater reliability scores for each metric and its interpretation [77].

\begin{tabular}{lll}
\hline Metric (type) & Cohen's Kappa coefficient & Interpretation \\
\hline Originality (ordinal) & 0.16 & Slight \\
\hline Feasibility (ordinal) & 0.76 & Substantial \\
\hline Practicality (ordinal) & 0.11 & Slight \\
\hline Overall quality (ordinal) & 0.06 & Slight \\
\hline Conformity to bicycles (nominal) & 0.71 & Substantial \\
\hline Conformity to modularity (nominal) & 0.76 & Substantial \\
\hline Modularity level (ordinal) & 0.43 & Moderate \\
\hline
\end{tabular}

In the second part of the analysis, one evaluator inspected all ideas and inductively derived a set of 67 tags that collectively described all the underlying approaches for solving the problem observed in the ideas. One or more tags were assigned to each of the ideas, and these tags were later grouped into 15 high-level tags of similar approaches. The tag structure (67 low-level and 15 high-level tags) and the assignment of tags to ideas were finally reviewed by two other evaluators and discussed until a consensus was reached among the three evaluators. Examples of tags are 'making bikes grow (by twisting) and 'discouraging bike use' (by sabotaging cyclists), where the brackets enclose the low-level tag in each case. The analysis of the tags helped us to visualize how each participant explored the solution space and to identify the tags that were seldom applied to the participants' ideas (i.e. tags that appeared the least among all ideas). This allowed us to calculate both the diversity and the commonness of solutions. Diversity is given per participant and was calculated by counting how many low- and high-level tags we identified in the work of each participant (we report both low- and highlevel tag diversity per group). Commonness is given per tag and was calculated by counting how many instances of each low-level tag there were among all ideas (we report both the average and the lowest commonness score per group). Note that we assigned tags to ideas rather than assigning the ideas into groups or 'bins' $[78,79]$ because ideas were commonly associated with multiple approaches. As such, one idea could have multiple tags, representing how that single idea explored different areas of the solution space. See the appendix for a list of all tags used in the analysis and how they appeared in the work of each participant. 
In summary, the participants' design work was assessed with respect to two sets of metrics, comprising creativity and fixation metrics. The set of creativity metrics consists of fluency (or quantity or number of ideas), given by the total number of ideas generated per participant); diversity (or variety or flexibility of ideas), given by the number of different tags assigned to each participant; and commonness (or usualness or unoriginality of ideas), given by the average and lowest commonness scores of the tags per participant. The set of fixation metrics consists of conformity to bicycle ideas (given by the number of bicycle ideas generated per participant) and conformity to modular ideas (given by the number of bicycle ideas generated per participant).

Thus, the analysis comprised measures that can be described as more objective (or quantitative, relatively easy to count) and more subjective (or qualitative, requiring some more judgment, even if the judgments are quantified). Table 4 summarizes the metrics used in the analysis.

Table 4. Summary of the final metrics incorporated into the analysis

\begin{tabular}{lllll}
\hline $\begin{array}{l}\text { Set of } \\
\text { metrics }\end{array}$ & Metric & $\begin{array}{l}\text { Type of } \\
\text { data used }\end{array}$ & Measurement & Granularity \\
\hline Creativity & Fluency & Idea sheets & Number of ideas & $\begin{array}{l}\text { Idea count per } \\
\text { participant }\end{array}$ \\
\hline Creativity & Diversity & $\begin{array}{l}\text { Tags derived } \\
\text { from ideas }\end{array}$ & $\begin{array}{l}\text { The number of non-redundant } \\
\text { low-level tags (out of 67) and high- } \\
\text { level tags (out of 15) identified }\end{array}$ & $\begin{array}{l}\text { Tag count per } \\
\text { participant }\end{array}$ \\
\hline Creativity & Commonness & $\begin{array}{l}\text { Low-level } \\
\text { tags derived } \\
\text { from ideas }\end{array}$ & $\begin{array}{l}\text { Average and lowest scores given to } \\
\text { tags based on their frequency, } \\
\text { ranging from 1 (uncommon tag) to } \\
\text { 43 (common tag) }\end{array}$ & $\begin{array}{l}\text { Tag score per } \\
\text { participant }\end{array}$ \\
& & Idea sheets & $\begin{array}{l}\text { Number and proportion of ideas } \\
\text { that are bicycles }\end{array}$ & $\begin{array}{l}\text { Idea count per } \\
\text { participant }\end{array}$ \\
\hline Fixation & $\begin{array}{l}\text { Conformity (to } \\
\text { bicycles) }\end{array}$ & Idea sheets & $\begin{array}{l}\text { Number and proportion of ideas } \\
\text { that are modular }\end{array}$ & $\begin{array}{l}\text { Idea count per } \\
\text { participant }\end{array}$ \\
\hline Fixation & $\begin{array}{l}\text { Conformity (to } \\
\text { modularity) }\end{array}$ & Idicand \\
\hline
\end{tabular}

\section{Results and discussion}

As the data is not normally distributed, we used ANOVA with significance values estimated using bootstrapping (i.e. resampling with replacement) and planned contrasts, a non-parametric version of the regular ANOVA test. Bootstrapping is a robust, widely used technique for determining sampling distributions of parameter estimates with non-normal distributions [80-83] and therefore well-suited for the current study. The results obtained from this approach were also found to be consistent with 
both a Kruskal-Wallis test followed by planned pairwise Mann-Whitney $U$ tests and a generalized linear model adopting log link function and Poisson distribution, thus being robust to variation in the statistical analysis.

The choice of contrasts. For the creativity set of metrics, we used three contrasts. The first contrast compared the baseline group to the stimulated groups (property, example, and mixed). The second contrast compared the mixed group to both the property and the example groups. The final contrast compared these last two groups. For the fixation set of metrics, we used two different sets of contrasts. When analyzing the conformity to bicycles, the first contrast compared groups exposed to the bicycle stimulus (example and mixed) to groups from which it was withheld (baseline and property), and the second and third contrasts compared groups in each of these pairings. Similarly, when analyzing the conformity to modularity, the first contrast compared groups exposed to the modularity stimulus (property and mixed) to groups not exposed to it (baseline and example), and the second and third contrasts compared groups in each of these pairings. When comparing one group to multiple groups, the means of the multiple groups are averaged for the contrasts.

\section{Fluency: exposure to external stimuli had a marginally significant effect on the number of ideas}

generated. A one-way ANOVA with total number of ideas (per participant) as the dependent variable using 1000 bootstrap resamples showed no significant differences across the groups, $F(3,56)=2.10, p$ $=.110, \eta^{2}=.101$. However, there was a significant trend, $F(3,56)=6.217, p=.016$, indicating that fluency results decreased linearly from the baseline to the mixed group. Planned contrasts showed a marginally significant difference between the baseline group and all other groups, $t=1.92, p=.067, d$ $=.56$, and between the mixed group and both the property and the example groups for the number of ideas generated per participant, with participants in the mixed group generating fewer ideas, $t=1.53$, $p=.097, d=.51$. These non-significant results are likely to reflect the small sample size because these means gave rise to moderate effect sizes. Table 5 shows summary statistics for fluency results. 
Table 5. Fluency across all conditions (or the number of ideas generated)

\begin{tabular}{lcccc}
\hline Generated ideas & Baseline & Property & Example & Mixed \\
\hline Total number of ideas & 155 & 137 & 126 & 104 \\
\hline Mean (and SD) for the number of ideas & 10.33 & 9.13 & 8.4 & 6.93 \\
per participant & $(3.96)$ & $(3.98)$ & $(3.89)$ & $(3.33)$ \\
\hline
\end{tabular}

These results reveal that the idea generation rate was not influenced by the type of stimulus seen (i.e. a concrete example design and an abstract system property), but by seeing any stimulus (either concrete or abstract) and by the number of stimuli seen (one or two stimuli). The first effect, i.e. seeing any stimulus, is consistent with studies in which seeing an example caused reduction in the idea fluency [11], although other studies have also reported an increase in the idea fluency as a result from external stimulation [84] or even no effect at all [5]. The second effect, i.e. seeing multiple stimuli, is inconsistent with previous research arguing that several different kinds of stimuli can be a means to avoid fixation and increase the number of final concepts [40], but consistent with other studies showing that exposure to several example solutions can actually further inhibit creativity instead of enhancing it [8]. Whilst the difference in fluency between the property and the example groups did not reach significance, fluency rates decreased when participants were presented with an example design instead of a system property. One possible interpretation is that the modularity property provided indirect approaches to solve the problem without defining a specific range of possible solutions as much as the bicycle example. As such, the results confirm both our fluency expectation across groups (see Table 1) and the conceptual gravity prediction, which stated that participants exposed to both stimuli would generate fewer ideas. Finally, these results also support our prediction of beneficial isolation, which stated that participants not exposed to stimuli would present the best fluency results.

Diversity: exposure to external stimuli had a marginally significant effect on the number of lowlevel tags explored and a significant effect on the number of high-level tags explored. For the number of low-level tags identified in the participants' work, a one-way ANOVA with total number of low-level tags as the dependent variable using 1000 bootstrap resamples showed a marginally significant difference across the groups, $F(3,56)=2.39, p=.078, \eta^{2}=.113$. Planned contrasts revealed 
a significant difference between the baseline group and the three stimulated groups for the number of low-level tags identified, with baseline participants exploring a greater number of low-level tags, $t=$ $2.09, p=.041, d=.64$. For the number of high-level tags identified in the participants' work, a one-way ANOVA with total number of high-level tags as the dependent variable using 1000 bootstrap resamples showed significant differences across the groups, $F(3,56)=4.27, p=.009, \eta^{2}=.186$. Planned contrasts revealed a significant difference between the baseline group and the three stimulated groups, with baseline participants exploring a greater number of high-level tags, $t=2.42, p=.019, d=.73$; and a significant difference between the mixed group and both the property and the example groups, with participants in the mixed group exploring a lower number of high-level tags, $t=2.26, p=.028, d=.77$. Table 6 shows summary statistics for diversity results.

Table 6. Diversity across all conditions (or the exploration of the solution space)

\begin{tabular}{lcccc}
\hline Assigned tags & Baseline & Property & Example & Mixed \\
\hline Total number of low-level tags & 161 & 143 & 136 & 115 \\
\hline $\begin{array}{l}\text { Mean (and SD) for the number of low-level tags per } \\
\text { participant }\end{array}$ & 10.73 & 9.53 & 9.07 & 7.67 \\
& $(3.63)$ & $(3.70)$ & $(2.94)$ & $(2.19)$ \\
\hline $\begin{array}{l}\text { Total number of non-redundant low-level tags identified } \\
\text { (out of 67) }\end{array}$ & 54 & 51 & 49 & 38 \\
\hline Total number of high-level tags & 77 & 71 & 58 & 46 \\
\hline $\begin{array}{l}\text { Mean (and SD) for the number high-level tags per } \\
\text { participant }\end{array}$ & 5.13 & 4.73 & 3.87 & 3.07 \\
$\begin{array}{l}\text { Total number of non-redundant high-level tags } \\
\text { identified (out of 15) }\end{array}$ & $12.00)$ & $(1.79)$ & $(1.51)$ & $(1.58)$ \\
\hline
\end{tabular}

Consistent with the fluency results, the diversity results reveal that the exploration of the solution space was not influenced by the type of stimulus seen, but by the exposure to any example and by the number of stimuli seen. The first finding is consistent with many design creativity experiments, which found that the presence of a stimulus reduced the diversity of the ideas generated by participants because the participants were confined to solutions similar to the stimulus seen $[11,66,85]$. On the other hand, the second finding is inconsistent with previous research, which stated that diverse stimuli can activate different aspects of a participant's knowledge, thus encouraging an increased diversity of ideas [39]. However, it can be argued that the two stimulus used in this experiment were not 
sufficiently diverse, thus not increasing significantly the diversity of ideas. Whilst the results for the diversity of non-redundant high- and low-level tags were approximately the same across the first three groups (baseline, property, and example), the average number of such tags identified per participant decreased when participants were exposed to any stimuli and when presented with the two stimuli. Also, problem exploration decreased when participants were presented with an example design instead of a system property. One possible interpretation is that exposure to the modularity property allowed participants to apply that property in more diverse areas of the solution space when compared to their response to the bicycle example. As such, the results confirm our diversity expectation (see Table 1) and support our prediction of beneficial isolation, which stated that participants not exposed to stimuli would present the best diversity results.

\section{Commonness: exposure to external stimuli had no effect on either the average nor on the lowest} commonness score per participant. For average commonness score, a one-way ANOVA with average scores as the dependent variable using 1000 bootstrap resamples showed non-significant differences across the groups, $F(3,56)=1.67, p=.183, \eta^{2}=.082$. However, planned contrasts showed a significant difference between the mixed group and both the property and the example groups for the average commonness score, with participants in the mixed group having a higher score for the low-level tags used, $t=2.14, p=.037, d=.67$. For the lowest commonness score, a one-way ANOVA with the lowest scores as the dependent variable using 1000 bootstrap resamples showed non-significant differences across the groups, $F(3,56)=2.08, p=.113, \eta^{2}=.100$. However, consistent with the average commonness scores, planned contrasts showed a significant difference between the mixed group and both the property and the example groups for the lowest score, with participants in the mixed group having again a higher commonness score for the low-level tags used, $t=2.39, p=.020, d=.74$. Table 7 shows summary statistics for commonness results.

Table 7. Commonness across all conditions (or the unoriginality in the solution space exploration) 


\begin{tabular}{lcccc}
\hline Commonness scores & Baseline & Property & Example & Mixed \\
\hline Mean (and SD) for the average commonness score per & 17.29 & 16.06 & 17.05 & 19.36 \\
participant & $(3.59)$ & $(3.24)$ & $(3.76)$ & $(5.58)$ \\
\hline Mean (and SD) for the lowest commonness score per & 4.2 & 4 & 4.13 & 6.93 \\
participant & $(3.10)$ & $(2.10)$ & $(2.36)$ & $(6.17)$ \\
\hline
\end{tabular}

In contrast to both fluency and diversity results, commonness results reveal that the occurrence of uncommon ideas (here interpreted from the low-level tags) was not influenced by exposure to stimuli. This confounded our expectation that all metrics in the creativity set (fluency, diversity, and commonness) would yield similar results, as these are not mutually independent metrics. It can be argued that our results differ from those of many design creativity experiments because of the measurement adopted. Whereas studies often use a marking scheme in which judges give a score to an idea $[13,27,53]$, we derived our commonness metric from the previous diversity analysis, in which we used tags identified in the participants' work. Accordingly, in this experiment we analyzed the commonness of ideas and not the novelty or originality, i.e. we measured the frequency of ideas, which shows how usual they are in the set of all generated ideas [86]. This is a more objective metric, since measuring novelty or originality would require comparing each idea to all known solutions to the design problem. Whereas the mixed group produced the worst results (i.e. higher commonness scores), we cannot see any trend within the results from the other groups with respect to the presence or type of stimulus. As such, the results do not confirm our commonness expectation (see Table 1) nor support our prediction of beneficial isolation, which stated that participants not exposed to stimuli would yield the best commonness results.

\section{Conformity (repetition of bicycle and modular ideas): exposure to external stimuli had a significant effect on the proportions of both bicycle and modular ideas generated per} participant. A one-way ANOVA with total number of bicycle ideas as the dependent variable using 1000 bootstrap resamples showed no significant differences across the groups, $F(3,56)=.527, p=$ $.666, \eta^{2}=.027$, a finding that was repeated for the total number of modular ideas, $F(3,56)=1.43, p=$ $.244, \eta^{2}=.071$. Planned contrasts did not reveal any significant differences between groups. However, 
Chi-squared tests for comparison of frequencies showed a significant difference in the proportions of bicycle ideas, $\chi^{2}(3, N=522)=11.3, p=.010, \varphi=.147$, and modular ideas, $\chi^{2}(3, N=522)=7.80, p=$ $.050, \varphi=.122$, generated across groups. A significant difference was also found for the proportion of bicycle ideas generated between groups exposed to the bicycle stimulus (example and mixed) and groups from which it was withheld (baseline and property), $\chi^{2}(1, N=522)=10.2, p=.001, \varphi=.140$; and for the proportion of modular ideas generated between groups exposed to the modularity stimulus (property and mixed) and groups not exposed to it (baseline and example), $\chi^{2}(1, N=522)=4.34, p=$ $.037, \varphi=.091$. To avoid exaggerating group differences driven by a few individuals, additional one-way ANOVAs were incorporated into the analysis, with the average proportion of bicycle and modular ideas as the dependent variable and using 1000 bootstrap resamples. The results showed significant differences in the proportion of bicycle ideas across groups $F(3,56)=2.80, p=.048, \eta^{2}=.130$. Planned contrasts showed that this result is driven by a difference between groups exposed to the bicycle stimulus (example and mixed) and groups from which it was withheld (baseline and property), with participants exposed to the bicycle sketch generating a higher proportion of bicycle ideas, $t=$ $-2.60, p=.017, d=.67$. Additionally, there were marginally significant differences for the average proportion of modular ideas, $F(3,56)=2.65, p=.057, \eta^{2}=.124$. Planned contrasts showed that this result is driven by a marginal difference between the property group and the mixed group, $t=-2.25, p$ $=.055, d=.71$, with the mixed group generating a higher proportion of modular ideas. Table 8 shows summary statistics for conformity results.

Table 8. Conformity across all conditions (or repetition of idea types)

\begin{tabular}{lcccc}
\hline Bicycle ideas and modular ideas & Baseline & Property & Example & Mixed \\
\hline Total number of bicycle ideas (within the group) & 67 & 52 & 67 & 59 \\
\hline Mean (and SD) for the number of bicycle ideas per & 4.47 & 3.47 & 4.47 & 3.93 \\
participant & $(2.67)$ & $(2.33)$ & $(2.88)$ & $(2.37)$ \\
\hline Proportion of bicycle ideas (within the group) & .43 & .38 & .53 & .57 \\
\hline Mean (and SD) for the proportion of bicycle ideas per & .45 & .36 & .54 & .58 \\
participant & $(.22)$ & $(.20)$ & $(.24)$ & $(.23)$ \\
\hline Total number of modular ideas (within the group) & 28 & 27 & 17 & 29 \\
\hline Mean (and SD) for the number of modular ideas per & 1.87 & 1.8 & 1.13 & 1.93 \\
participant & $(1.13)$ & $(1.52)$ & $(0.64)$ & $(1.33)$ \\
\hline
\end{tabular}




\begin{tabular}{lcccc}
\hline \hline Total proportion of modular ideas (within the group) & .18 & .20 & .13 & .28 \\
\hline Mean (and SD) for the proportion of bicycle ideas per & .21 & .18 & .16 & .33 \\
participant & $(.15)$ & $(.13)$ & $(.14)$ & $(.25)$ \\
\hline
\end{tabular}

These results indicate that conformity was influenced by the type of stimulus seen, i.e. each stimulus encouraged the generation of ideas of the same type across the groups. This is fairly consistent with previous research showing that participants tend to repeat or incorporate the stimulus seen, in part or in full, into their own ideas $[29,43,57]$. However, this finding seems to be driven mostly by the mixed group results, as the frequency of bicycle ideas was not significantly different between the baseline and the example groups, nor was the frequency of modular ideas significantly different between the baseline and the property groups. This might reinforce the idea of conceptual gravity, with the mixed group generating the highest frequencies of bicycle and modular ideas, thus being 'doubly fixated' and possibly drawn too much towards the lifecycle property of adaptability. Based on previous research [87], we predicted that inspiration or fixation effects from example designs would prevail when compared to those of system properties. However, our results do not support this. Table 8 shows that whilst the mixed group generated more bicycle ideas than modular ideas overall, the increase in the frequency of modular ideas in this group was proportionally larger than the frequency of bicycle ideas in the same group. This would seem to suggest a potential for property prevalence (i.e. participants in the mixed group were more influenced by the modularity property than by the bicycle example design), although this is a purely descriptive observation, which could not be confirmed with our existing data. Also, the total number of modular ideas was roughly the same between the baseline and the property groups, whereas the number of bicycle ideas was roughly the same between the baseline and the example groups, meaning that the occurrence of such ideas did not increase much depending on the stimulus seen. However, the occurrence of modular ideas in the example group and bicycle ideas in the property group dropped considerably when compared to the baseline, which indicates that the property group was pushed away from bicycle ideas just as the example group was deviated from modular ideas, ideas that would appear more often otherwise (as shown by baseline results). Finally, the results partially support our conformity expectation (see Table 1) and partially support our 
prediction of beneficial isolation, which stated that participants not exposed to stimuli would present the best conformity results. Figure 3 illustrates a selection of participants' ideas that were (A) bicycles, (B) not bicycles, (C) modular, and (D) not modular.

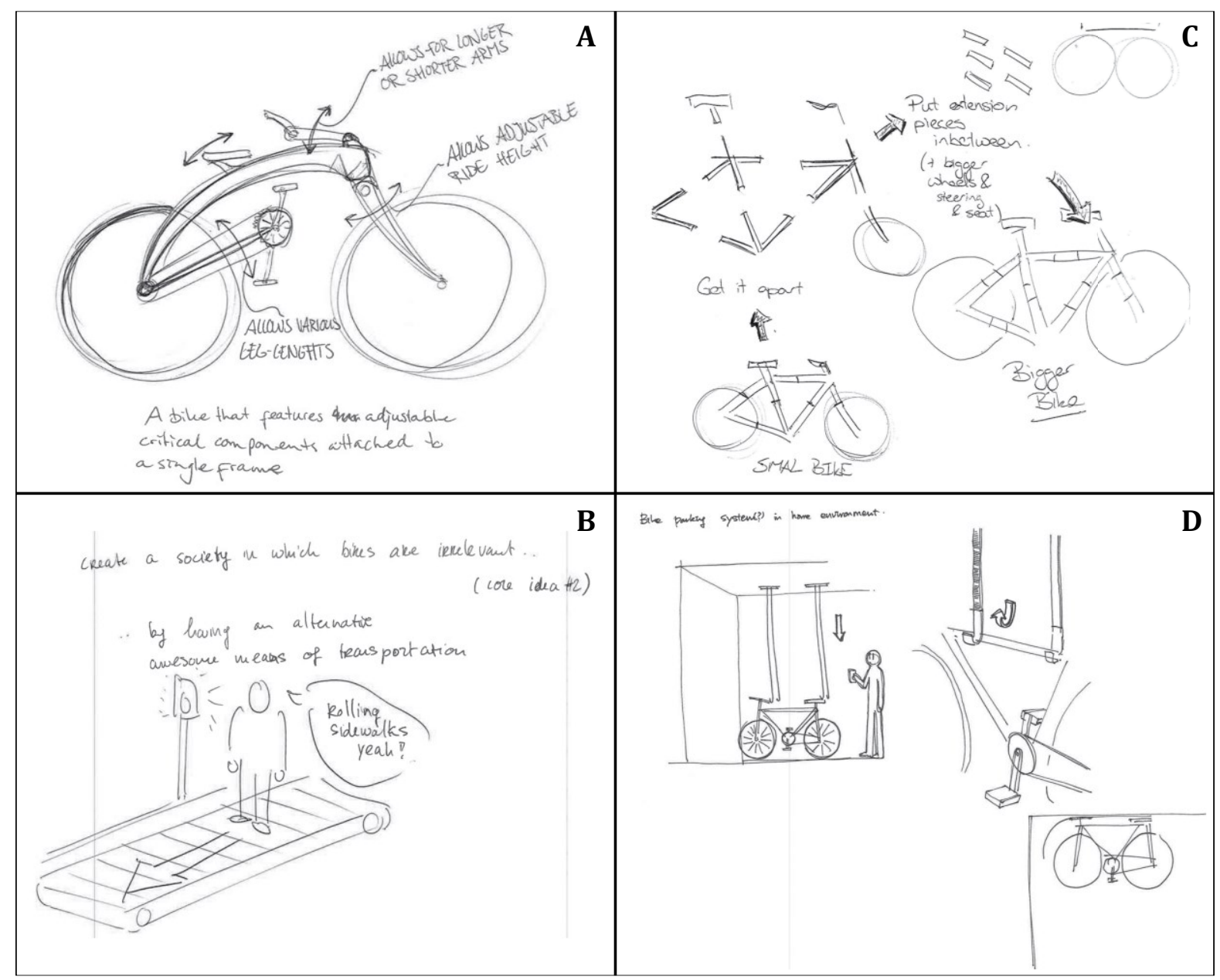

Fig. 3. (A) Bicycle idea, (B) non-bicycle idea, (C) modular idea, and (D) non-modular idea.

We also examined whether the degree of conformity would mediate the effects of stimulation on diversity. We used the model 4 PROCESS macro for SPSS [83] with stimuli as a multi-categorical independent variable for estimating mediation. For high-level tags, the results show that bicycle conformity was a significant mediator for the influence of stimuli on diversity $\beta=-.20, t=-2.20, p=.03$, CI [-.38; -.02], whereas modularity conformity was not, $\beta=-.29, t=-1.96, p=.10$, CI [-.63; 05]. For lowlevel tags, no significant mediating effects were present $(p>.10)$. This means that the diversity results can be partially explained by the repetition of bicycle ideas across the participants' ideas. 
Summary of the results. Except for commonness, the creativity metrics in this study (i.e. fluency and diversity) supported our predictions: participants exposed to stimuli tended to create fewer and less diverse ideas when compared to participants who were not exposed to any stimuli. As such, these results partially confirm what we predicted and defined as beneficial isolation. Also, participants exposed to both stimuli produced the worst results, which confirms what we defined as conceptual gravity. This shows that idea generation was hindered by exposure to both a concrete example and an abstract property. With respect to the fixation metrics (i.e. the repetition of the stimulus), conformity to both the bicycle example and the modular property was observed, which does not support what we defined as example prevalence.

\section{Limitations and future work}

The idea generation session in this study was thirty minutes long, which is typical of creativity experiments but short when compared to many activities within design practice [15]. Different results might be expected for a longer procedure, as novel ideas tend to occur later in the idea generation session [88]. The participants in this study were graduate students in Industrial Design Engineering who had been practicing design for less than five years on average, and therefore should be considered novice designers. Different results might be expected from participants with different disciplinary backgrounds $[12,89]$ and different levels of experience $[41,90]$. Both the design problem and the brief given to the participants had low levels of complexity. Different results might be expected when the problem is more complex, resulting in a more involved design process [7]. The design work was assessed by evaluating initial concepts according to relatively simple metrics. Different results might be expected when evaluating refined concepts against other metrics such as practicality and ease of use $[53,91]$, which are also likely to determine the success of a product. The sample size used in this study can be considered typical for design creativity experiments, however as with those other studies, this research would benefit from a larger number of participants to strengthen the claims made. 
In developing the two stimuli for this experiment (the concrete example and the abstract property), we sought stimuli that exhibited the same underlying property (i.e. adjustability) for better comparison between groups, while still allowing us to observe the effects of being exposed to both stimuli together without redundancy in what the stimuli represent. Adjustability and modularity are two ways of achieving adaptability, and as represented in the stimuli they also have similar relevance or proximity to the problem: an adjustable bicycle is just as close to the problem as a modular bicycle is (as we could observe in the proportions of such ideas in the baseline group). Overall, the stimuli used here were similar in many ways: in terms of representation (image and verbal description) and fidelity (line drawings), quantity (only one for the two comparison groups), potential for originality (novel ways to make bikes adaptable), proximity to the problem (similar applicability of inspiration sources), and underlying property (adjustability). However, in representing two different approaches to adaptability, it can be argued that the content is being confounded with the level of abstraction. Accordingly, we acknowledge that we do not provide a clear manipulation of abstraction levels here; instead, we offer a comparison of inspiration effects from a typical example design and a common system property. Future work might productively use two additional stimuli to control for this issue, for example with a modular example design and a diagrammatic representation of adjustability. Careful experiment design and analysis might then allow researchers to neatly separate the effects content and abstraction. It is also important to notice that the distinction used in this study for the inspiration sources is not absolute. The division of stimuli into example designs and system properties based on their level of abstraction is just one of many other possible divisions, such as the modality of representation, and proximity to the design problem, as already outlined in the literature [7]. Also, most of these divisions are not mutually exclusive, as stimuli are likely to move along a continuum between any two bipolar parameters.

Finally, participants exposed to both stimuli in this experiment were first given the bicycle example design and then the modularity system property. Previous research has found that participants given a concrete example and asked to generate a provisional abstract version of it produced final concrete solutions with increased originality [71]. This suggests that generating an abstract solution first and 
then moving to more concrete solutions is an effective way to increase creativity in design. Other studies could use a different experimental setup to investigate this hypothesis further. Future research could also use more naturalistic settings and incorporate more qualitative methods to generate a more complete report on the use of system properties in design practice. The inspiration effects from other properties could also be investigated to confirm whether the findings obtained for modularity can actually be generalized to other system properties. Such properties are often recommended in the engineering and design literature on the basis of experience or common sense, but this still requires thorough scientific validation in order to show how exactly they might help either the design process or the output. This study presents an initial effort to understand how these properties can influence the creative process but more research is needed to understand how they influence the design process more generally and the products that result from that. In this way, design research might not only promote the use of system properties but also understand the consequences of using them as inspiration sources.

\section{Conclusions}

Inspiration sources should be accessed carefully. This paper reports on a study of whether the inspiration and fixation effects resulting from exposure to an example design (as a concrete source) would also be found for a system property (as an abstract source). Whilst using example designs may help clarifying abstracted properties, it might also make such properties less general, reducing the open-endedness of design tasks and potentially inducing design fixation [92]. Despite this, in creativity experiments, researchers have largely used example designs as inspiration sources for designers, and have not yet compared the inspiration effects from example designs with those from system properties. Perhaps this is because researchers do not expect designers to look for such abstract properties, or maybe researchers assume that whatever properties are present in an example, these will be perceived by designers, thus making the explicit representation of such properties unnecessary. However, our results show how designers can be pushed away from a specific solution space depending on the 
inspiration source, so that the inspiration material should be carefully selected, otherwise designers might get diverted by irrelevant or even counterproductive sources.

\section{Abstract system properties can also be used to inspire designers, but designers should be aware of the cognitive overload of accessing additional inspiration sources. There is some evidence to} support the view that more concrete features are easier to recognize - and thus reproduce - than more abstract features, such as modularity [87] (for a similar view, also see $[17,18,71]$ ). However, the results reported here do not support this: conformity or repetition was approximately equivalent for both the example design and the system property. One possible explanation for this is that in our experiment we have made the abstract property explicit instead of assuming that designers would perceive it in a given product. Interestingly, when comparing the two types of conformities, the property conformity was less harmful to participants' fluency or diversity (although this contrast did not reach statistical significance). This can show how abstract system properties can be used to inspire and guide the design process while producing mild negative inspiration effects, a finding that is consistent with the related literature $[28,70,71,73]$. Also, if we note that the group exposed to both stimuli generated the higher proportions of both bicycle and modular ideas, that can tell us that these participants did not have enough time to move away from the influence of the stimuli and basically adhered to one idea and then to the other. As such, it is possible that the negative results produced by this mixed group are due to the incorporation of a second inspiration source halfway through idea generation, thus adding a significant cognitive load and ultimately impairing the creative process [28].

\section{Different stimuli types can fixate, but this is not necessarily bad, and such knowledge can}

influence design education and practice. In order to address the major hypothesis of this work, we have compared the inspiration and fixation effects from distinct stimuli: an example design and a system property. Based on the metrics chosen, we have found that effects were very similar for both stimuli types: participants generated an equivalent number of ideas, explored an equivalent area of the solution space (but not the same), generated an equivalent number of unusual ideas, and reproduced 
an equivalent number of ideas of the same type as the stimulus seen. However, when compared to those exposed to only one type of stimulus or none, designers exposed to both stimuli produced very different results for all metrics. Whereas these results can be associated with design fixation, they also represent an opportunity. If the aim of a design project is to explore distinct areas of the solution space in depth, instead of a larger area more shallowly, then providing designers with more than one stimuli can be efficient to limit the exploration of the solution space to areas around the stimuli presented, whether they are concrete example designs or abstract system properties. Ultimately, we could apply the results reported here to those practices that are concerned with inspirational stimuli, the form they should take, and how abstract they should be. Such practices include design education and design management, and also the development and implementation of design tools that provide designers with external stimuli.

\section{Acknowledgments}

This work was supported by the CAPES Foundation, Ministry of Education of Brazil (BEX 11468/13-0) and the UK's Engineering and Physical Sciences Research Council (EP/K008196/1). Research data supporting this publication is available from the University of Cambridge data repository: https://www.repository.cam.ac.uk/handle/1810/255005

\section{Appendix}

[QUALITATIVE TAG ANALYSIS - SEE LAST PAGE OF THIS DOCUMENT]

Matrix used in the analysis of diversity, representing the exploration of the solution space by each participant. Tag codes are listed in the first column with the associated tag descriptions in the last two columns. The experimental groups and participant numbers are listed across the top two rows. Where the cells of the matrix are shaded, this indicates that a particular tag was assigned to a particular participant's idea(s). 


\section{References}

[1] Goldschmidt, G., and Sever, A. L., 2011, "Inspiring design ideas with texts," Des. Stud., 32(2), pp. 139-155.

[2] Gonçalves, M., Cardoso, C., and Badke-Schaub, P., 2014, "What inspires designers?

Preferences on inspirational approaches during idea generation," Des. Stud., 35(1), pp. 29-53.

[3] Herring, S. R., Chang, C.-C., Krantzler, J., and Bailey, B. P., 2009, "Getting inspired!: understanding how and why examples are used in creative design practice," Proceedings of the SIGCHI Conference on Human Factors in Computing Systems, ACM, pp. 87-96.

[4] Jansson, D. G., and Smith, S. M., 1989, "Design fixation," Preprints : NSF Engineering Design Research Conference, Amherst, Massachusetts, pp. 53-76.

[5] Jansson, D. G., and Smith, S. M., 1991, "Design fixation," Des. Stud., 12(1), pp. 3-11.

[6] Youmans, R. J., and Arciszewski, T., 2014, "Design fixation: Classifications and modern methods of prevention," Artif. Intell. Eng. Des. Anal. Manuf., 28(02), pp. 129-137.

[7] Vasconcelos, L. A., and Crilly, N., 2016, "Inspiration and fixation: Questions, methods, findings, and challenges," Des. Stud., 42, pp. 1-32.

[8] Sio, U. N., Kotovsky, K., and Cagan, J., 2015, "Fixation or inspiration? A meta-analytic review of the role of examples on design processes," Des. Stud., 39, pp. 70-99.

[9] Chrysikou, E. G., and Weisberg, R. W., 2005, "Following the Wrong Footsteps: Fixation Effects of Pictorial Examples in a Design Problem-Solving Task.," J. Exp. Psychol. Learn. Mem. Cogn., 31(5), pp. 1134-1148.

[10] Goldschmidt, G., 2011, "Avoiding design fixation: transformation and abstraction in mapping from source to target," J Creat. Behav, 45(2), pp. 92-100.

[11] Linsey, J. S., Tseng, I., Fu, K., Cagan, J., Wood, K. L., and Schunn, C., 2010, "A Study of Design Fixation, Its Mitigation and Perception in Engineering Design Faculty,” J. Mech. Des., 132(4), p. 041003.

[12] Purcell, A. T., and Gero, J. S., 1996, "Design and other types of fixation," Des. Stud., 17(4), pp. 363-383.

[13] Siangliulue, P., Chan, J., Gajos, K. Z., and Dow, S. P., 2015, "Providing Timely Examples Improves the Quantity and Quality of Generated Ideas," ACM Press, pp. 83-92.

[14] Youmans, R. J., 2011, "The effects of physical prototyping and group work on the reduction of design fixation," Des. Stud., 32(2), pp. 115-138.

[15] Crilly, N., 2015, "Fixation and creativity in concept development: The attitudes and practices of expert designers," Design Studies, 38, pp. 54-91.

[16] Jang, J., and Schunn, C. D., 2012, "Physical Design Tools Support and Hinder Innovative Engineering Design,” J. Mech. Des., 134(4), pp. 041001-041001.

[17] Cheong, H., Hallihan, G., and Shu, L. H., 2014, "Understanding Analogical Reasoning in Biomimetic Design: An Inductive Approach,” Design Computing and Cognition '12, J.S. Gero, ed., Springer Netherlands, Dordrecht, pp. 21-39.

[18] Feng, T., Cheong, H., and Shu, L. H., 2014, "Effects of Abstraction on Selecting Relevant Biological Phenomena for Biomimetic Design,” J. Mech. Des., 136(11), p. 111111.

[19] Pahl, G., and Beitz, W., 1996, Engineering design: a systematic approach, Springer, London; New York.

[20] Chen, C.-C., and Crilly, N., 2014, "Modularity, redundancy and degeneracy: Cross-domain perspectives on key design principles," Systems Conference (SysCon), 2014 8th Annual IEEE, IEEE, pp. 546-553.

[21] McManus, H., Richards, M., Ross, A., and Hastings, D., 2007, “A Framework for Incorporating 'ilities' in Tradespace Studies,”," AIAA Space, pp. 941-954. 
[22] de Weck, O. L., Ross, A. M., and Rhodes, D. H., 2012, "Investigating relationships and semantic sets amongst system lifecycle properties (Ilities)," Third International Conference on Engineering Systems, TU Delft, the Netherlands, Citeseer.

[23] Schoettl, F., and Lindemann, U., 2014, "Design for System Lifecycle Properties - A Generic Approach for Modularizing Systems," Procedia Comput. Sci., 28, pp. 682-691.

[24] Eastman, C., 2001, "New directions in design cognition: studies of representation and recall," Des. Knowing Learn. Cogn. Des. Educ., pp. 147-198.

[25] Boden, M. A., 1994, "What is creativity," Dimens. Creat., pp. 75-117.

[26] Hofstadter, D. R., 2001, "Analogy as the core of cognition," Analog. Mind Perspect. Cogn. Sci., pp. 499-538.

[27] Cheng, P., Mugge, R., and Schoormans, J. P. L., 2014, “A new strategy to reduce design fixation: Presenting partial photographs to designers," Des. Stud., 35(4), pp. 374-391.

[28] Moreno, D. P., Hernández, A. A., Yang, M. C., Otto, K. N., Hölttä-Otto, K., Linsey, J. S., Wood, K. L., and Linden, A., 2014, "Fundamental studies in Design-by-Analogy: A focus on domain-knowledge experts and applications to transactional design problems," Des. Stud., 35(3), pp. 232-272.

[29] Tseng, I., Moss, J., Cagan, J., and Kotovsky, K., 2008, “Overcoming blocks in conceptual design: the effects of open goals and analogical similarity on idea generation," ASME 2008 International Design Engineering Technical Conferences and Computers and Information in Engineering Conference, American Society of Mechanical Engineers, pp. 3-9.

[30] Hernandez, N. V., Schmidt, L. C., and Okudan, G. E., 2013, "Systematic ideation effectiveness study of TRIZ," J. Mech. Des., 135(10), p. 101009.

[31] Chakrabarti, A., Sarkar, P., Leelavathamma, B., and Nataraju, B. S., 2005, "A functional representation for aiding biomimetic and artificial inspiration of new ideas," Artif. Intell. Eng. Des. Anal. Manuf., 19(2), pp. 113-132.

[32] Linsey, J., and Wood, K., 2007, "Wordtrees: a method for design-by-analogy." American Society for Engineering Education Annual Conference, Pittsburg, PA.

[33] Vattam, S., Wiltgen, B., Helms, M., Goel, A. K., and Yen, J., 2011, “DANE: Fostering Creativity in and through Biologically Inspired Design," Design Creativity 2010, T. Taura, and Y. Nagai, eds., Springer London, pp. 115-122.

[34] Mohan, M., Chen, Y., and Shah, J. J., 2011, "Towards a framework for holistic ideation in conceptual design," ASME 2011 International Design Engineering Technical Conferences and Computers and Information in Engineering Conference, American Society of Mechanical Engineers, pp. 661-672.

[35] Sarkar, P., and Chakrabarti, A., 2008, "The effect of representation of triggers on design outcomes," AI EDAM, 22(02).

[36] Dugosh, K. L., Paulus, P. B., Roland, E. J., and Yang, H. C., 2000, “Cognitive stimulation in brainstorming," J. Pers. Soc. Psychol., 79(5), pp. 722-735.

[37] Dugosh, K. L., and Paulus, P. B., 2005, "Cognitive and social comparison processes in brainstorming," J. Exp. Soc. Psychol., 41(3), pp. 313-320.

[38] Liikkanen, L. A., and Perttula, M., 2010, "Inspiring design idea generation: insights from a memory-search perspective," J. Eng. Des., 21(5), pp. 545-560.

[39] Nijstad, B. A., Stroebe, W., and Lodewijkx, H. F., 2002, "Cognitive stimulation and interference in groups: Exposure effects in an idea generation task," J. Exp. Soc. Psychol., 38(6), pp. 535-544.

[40] Perttula, M. K., and Liikkanen, L. A., 2006, "Exposure effects in design idea generation: unconscious conformity or a product of sampling probability," Proceedings of NordDesign, pp. $42-55$.

[41] Dahl, D. W., and Moreau, P., 2002, "The Influence and Value of Analogical Thinking during New Product Ideation,” J. Mark. Res., 39(1), pp. 47-60. 
[42] Perttula, M., and Sipilä, P., 2007, “The idea exposure paradigm in design idea generation," J. Eng. Des., 18(1), pp. 93-102.

[43] Smith, S. M., Ward, T. B., and Schumacher, J. S., 1993, "Constraining effects of examples in a creative generation task," Mem. Cognit., 21(6), pp. 837-845.

[44] Duncker, K., 1945, “On problem-solving.," Psychol. Monogr., 58(5), p. i.

[45] Luchins, A. S., 1942, "Mechanization in problem solving: The effect of Einstellung.," Psychological monographs, 54(6), p. i.

[46] Maier, N. R., 1931, "Reasoning in humans. II. The solution of a problem and its appearance in consciousness.," J. Comp. Psychol., 12(2), p. 181.

[47] Moreno, D. P., Yang, M. C., Hernández, A. A., Linsey, J. S., and Wood, K. L., 2015, “A Step Beyond to Overcome Design Fixation: A Design-by-Analogy Approach,” Design Computing and Cognition'14, Springer, pp. 607-624.

[48] Smith, S. M., and Linsey, J., 2011, "A Three-Pronged Approach for Overcoming Design Fixation,” J. Creat. Behav., 45(2), pp. 83-91.

[49] Helms, M., and Goel, A. K., 2014, "The Four-Box Method: Problem Formulation and Analogy Evaluation in Biologically Inspired Design,” J. Mech. Des., 136(11), p. 111106.

[50] Helms, M., and Goel, A. K., 2014, "Analogical Problem Evolution in Biologically Inspired Design," Design Computing and Cognition '12, Springer Netherlands, pp. 3-19.

[51] Vincent, J. F. V., Bogatyreva, O. A., Bogatyrev, N. R., Bowyer, A., and Pahl, A.-K., 2006, "Biomimetics: its practice and theory," J. R. Soc. Interface, 3(9), pp. 471-482.

[52] Vasconcelos, L. A., Crilly, N., Chen, C.-C., Campos, F., and Kelner, J., 2016, "What's the benefit of problem exploration?," DS 84: Proceedings of the DESIGN 2016 14th International Design Conference, The Design Society, Cavtat, Dubrovnik, Croatia, pp. 89 - 98.

[53] Cardoso, C., and Badke-Schaub, P., 2011, "The influence of different pictorial representations during idea generation," J. Creat. Behav., 45(2), pp. 130-146.

[54] Viswanathan, V., and Linsey, J., 2013, "Examining design fixation in engineering idea generation: the role of example modality," Int. J. Des. Creat. Innov., 1(2), pp. 109-129.

[55] Lujun, Z., 2011, "Design fixation and solution quality under exposure to example solution," Computing, Control and Industrial Engineering (CCIE), 2011 IEEE 2nd International Conference on, IEEE, pp. 129-132.

[56] Perttula, M. K., and Liikkanen, L. A., 2006, "Structural Tendencies and Exposure Effects in Design Idea Generation," pp. 199-210.

[57] Viswanathan, V., Atilola, O., Esposito, N., and Linsey, J., 2014, "A study on the role of physical models in the mitigation of design fixation," J. Eng. Des., 25(1-3), pp. 25-43.

[58] Taysom, E., and Crilly, N., 2014, "Diagrammatic Representation of System Lifecycle Properties," 4th International Engineering Systems Symposium.

[59] Chen, C.-C., and Crilly, N., 2014, "Towards a framework of design principles: Classifying system features, behaviours and types." DRS 2014.

[60] Baldwin, C. Y., and Clark, K. B., 2000, Design Rules, Vol. 1: The Power of Modularity, The MIT Press, Cambridge, Mass.

[61] Ulrich, K. T., and Eppinger, S. D., 2007, Product Design and Development, McGraw-Hill Education Singapore, Boston.

[62] Altshuller, G. S., 1984, Creativity as an Exact Science, Gordon and Breach, Amsterdam, NL.

[63] Eberle, B., 1996, Scamper: Games for Imagination Development, Prufrock Press Inc.

[64] Deldin, J.-M., and Schuknecht, M., 2014, "The AskNature Database: Enabling Solutions in Biomimetic Design,” Biologically Inspired Design, A.K. Goel, D.A. McAdams, and R.B. Stone, eds., Springer London, pp. 17-27.

[65] Cardoso, C., and Badke-Schaub, P., 2011, "Fixation or Inspiration: Creative Problem Solving in Design," J. Creat. Behav., 45(2), pp. 77-82. 
[66] Toh, C. A., and Miller, S. R., 2014, "The Impact of Example Modality and Physical Interactions on Design Creativity," J. Mech. Des., 136(9), p. 091004.

[67] Guerreiro Goncalves, M., Cardoso, C., and Badke-Schaub, P. G., 2012, "Find your inspiration: exploring different levels of abstraction in textual stimuli," Proceedings of the 2 nd international conference on design creativity (ICDC2012), Glasgow (UK), 18-20 Sept., 1-8., The Design Society.

[68] Chan, J., Fu, K., Schunn, C., Cagan, J., Wood, K., and Kotovsky, K., 2011, “On the benefits and pitfalls of analogies for innovative design: Ideation performance based on analogical distance, commonness, and modality of examples," J. Mech. Des., 133, p. 081004.

[69] Fu, K., Chan, J., Cagan, J., Kotovsky, K., Schunn, C., and Wood, K., 2013, "The Meaning of 'Near' and 'Far': The Impact of Structuring Design Databases and the Effect of Distance of Analogy on Design Output," J. Mech. Des., 135, p. 021007.

[70] Gentner, D., and Markman, A. B., 1997, "Structure mapping in analogy and similarity.," Am. Psychol., 52(1), p. 45.

[71] Zahner, D., Nickerson, J. V., Tversky, B., Corter, J. E., and Ma, J., 2010, “A fix for fixation? Rerepresenting and abstracting as creative processes in the design of information systems," Artif. Intell. Eng. Des. Anal. Manuf., 24(02), p. 231.

[72] Gordon, W. J. J., 1961, Synectics: The Development of Creative Capacity, Harper \& Brothers.

[73] Yilmaz, S., Seifert, C. M., and Gonzalez, R., 2010, "Cognitive heuristics in design: Instructional strategies to increase creativity in idea generation," Artif. Intell. Eng. Des. Anal. Manuf., 24(03), pp. 335-355.

[74] Ward, T. B., Patterson, M. J., and Sifonis, C. M., 2004, "The Role of Specificity and Abstraction in Creative Idea Generation," Creat. Res. J., 16(1), pp. 1-9.

[75] Yu, L., Kittur, A., and Kraut, R. E., 2014, "Distributed analogical idea generation: inventing with crowds," ACM Press, pp. 1245-1254.

[76] "Zee-K Ergonomic Bike by Gabriel Henrique Floss at Coroflot.com," Coroflot [Online]. Available: http://www.coroflot.com/gabrielfloss/zee-k-ergonomic-bike1. [Accessed: 06-Apr2016].

[77] Landis, J. R., and Koch, G. G., 1977, "The Measurement of Observer Agreement for Categorical Data," Biometrics, 33(1), p. 159.

[78] Linsey, J. S., Clauss, E. F., Kurtoglu, T., Murphy, J. T., Wood, K. L., and Markman, A. B., 2011, "An Experimental Study of Group Idea Generation Techniques: Understanding the Roles of Idea Representation and Viewing Methods," J. Mech. Des., 133(3), p. 031008.

[79] Viswanathan, V. K., and Linsey, J. S., 2013, "Role of sunk cost in engineering idea generation: an experimental investigation," J. Mech. Des., 135(12), p. 121002.

[80] Bone, P. F., Sharma, S., and Shimp, T. A., 1989, “A Bootstrap Procedure for Evaluating Goodness-of-Fit Indices of Structural Equation and Confirmatory Factor Models,” J. Mark. Res., 26(1), p. 105.

[81] Efron, B., and Tibshirani, R. J., 1994, An Introduction to the Bootstrap, CRC Press.

[82] Hair, J. F., Sarstedt, M., Ringle, C. M., and Mena, J. A., 2012, "An assessment of the use of partial least squares structural equation modeling in marketing research," J. Acad. Mark. Sci., 40(3), pp. 414-433.

[83] Hayes, A. F., 2013, Introduction to Mediation, Moderation, and Conditional Process Analysis: A Regression-Based Approach, Guilford Press.

[84] Purcell, A. T., and Gero, J. S., 1992, “Artificial Intelligence in Design Conference 1991 Special Issue Effects of examples on the results of a design activity," Knowledge-Based Systems, 5(1), pp. $82-91$.

[85] Tseng, I., Moss, J., Cagan, J., and Kotovsky, K., 2008, "The role of timing and analogical similarity in the stimulation of idea generation in design,” Des. Stud., 29(3), pp. 203-221. 
[86] Verhaegen, P.-A.-A., Vandevenne, D., and Duflou, J. R., 2012, “ORIGINALITY AND NOVELTY: A DIFFERENT UNIVERSE,” DS 70: Proceedings of DESIGN 2012, the 12th International Design Conference, Dubrovnik, Croatia, Croatia, pp. 1961-1966.

[87] Vasconcelos, L. A., Crilly, N., Chen, C.-C., and Taysom, E., 2016, "To copy or not to copy: the influence of instructions in design fixation experiments," Design Computing and Cognition '16, Springer, pp. 379-397.

[88] Kudrowitz, B., and Dippo, C., 2013, "Getting to the novel ideas: exploring the alternative uses test of divergent thinking," ASME 2013 International Design Engineering Technical Conferences and Computers and Information in Engineering Conference, American Society of Mechanical Engineers, pp. V005T06A013-V005T06A013.

[89] Agogué, M., Poirel, N., Pineau, A., Houdé, O., and Cassotti, M., 2014, "The impact of age and training on creativity: A design-theory approach to study fixation effects," Think. Ski. Creat., 11, pp. 33-41.

[90] Kim, J., and Ryu, H., 2014, "A Design Thinking Rationality Framework: Framing and Solving Design Problems in Early Concept Generation," Human-Computer Interact., 29(5-6), pp. 516553.

[91] Goldschmidt, G., and Smolkov, M., 2006, "Variances in the impact of visual stimuli on design problem solving performance,” Des. Stud., 27(5), pp. 549-569.

[92] Töre Yargin, G., and Crilly, N., 2015, "Information and interaction requirements for software tools supporting analogical design,” Artif. Intell. Eng. Des. Anal. Manuf., 29(02), pp. 203214. 


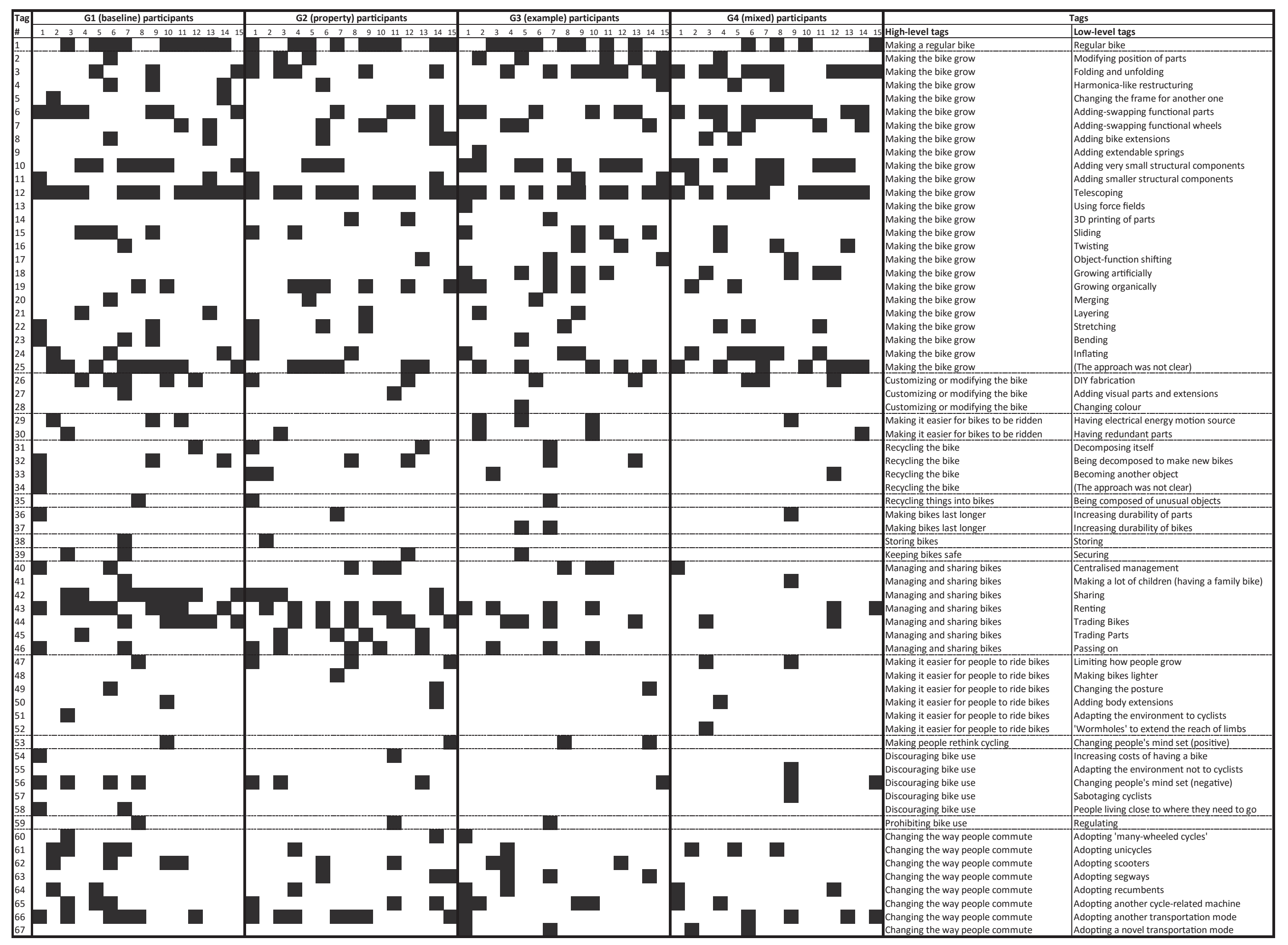

